\title{
NEW RECORDS OF BATS (Mammalia: Chiroptera) FROM CU LAO CHAM AND LY SON ARCHIPELAGOS, CENTRAL VIETNAM
}

\author{
Vu Dinh Thong ${ }^{1,2 *}$, Dao Nhan Loi ${ }^{3}$, Nguyen Thanh Luong ${ }^{1}$, \\ Hoang Quoc $\mathrm{Huy}^{4}$, Hoang Trung Thanh ${ }^{5,6}$ \\ ${ }^{1}$ Institute of Ecology and Biological Resources, VAST \\ ${ }^{2}$ Graduate University of Science and Technology, VAST \\ ${ }^{3}$ Tay Bac University, Son La province, Vietnam \\ ${ }^{4}$ Greenviet Biodiversity Conservation Centre, Da Nang, Vietnam \\ ${ }^{5}$ Faculty of Biology, VNU University of Science, Ha Noi, Vietnam \\ ${ }^{6}$ Centrer for Life Science Research, VNU University of Science, Ha Noi, Vietnam
}

\begin{abstract}
ABTRACT
$\mathrm{Cu}$ Lao Cham and Ly Son are two well-known archipelagos of Vietnam for their spectacular landscapes and diverse ecosystems including forest, cave, and agriculture. However, their bat fauna has received little attention. Between July 2017 and August 2018, we conducted a series of mammal surveys with emphasis on bats of these two archipelagos. Bats were captured by mist nets and harp traps. Echolocation calls of echolocating bats were recorded using the PCTape system then analysed by Selena software. With reference to all available literatures and specimens from the recent surveys, we obtained and confirmed records of nine bat species from $\mathrm{Cu}$ Lao Cham and three species from Ly Son. Of these, Megaderma spasma and Taphozous melanopogon are new to $\mathrm{Cu}$ Lao Cham while Rhinolophus macrotis is new to Ly Son. These three species were uncommon within $\mathrm{Cu}$ Lao Cham and Ly Son during our surveys and also rarely recorded from other islands of Vietnam. These new records not only expand the known distributional range but also provide worthwhile notes on a narrow geographical variation in morphology and echolocation of each species.
\end{abstract}

Keywords: Mammalia, conservation, echolocation, islands, taxonomy.

Citation: Vu Dinh Thong, Dao Nhan Loi, Nguyen Thanh Luong, Hoang Quoc Huy, Hoang Trung Thanh, 2018. New records of bats (Mammalia: Chiroptera) from Cu Lao Cham and Ly Son archipelagos, central Vietnam. Academia Journal of Biology, 40(4): 13-21. https://doi.org/10.15625/2615-9023/v40n4.13529.

*Corresponding author email: thongvudinh@gmail.com

Received 15 September 2018, accepted 5 December 2018

\section{INTRODUCTION}

$\mathrm{Cu}$ Lao Cham and Ly Son are well-known archipelagos of Vietnam for their spectacular landscapes with different habitats including caves (Thong, 2016; Thong et al., 2016b). Cu Lao Cham comprises eight islands: Hon Lao, Hon Dai, Hon Mo, Hon Kho Me, Hon Kho
Con, Hon La, Hon Tai and Hon Ong. Of these, Hon Lao is the largest and most important island for biodiversity conservation while seven remaining ones are small, mostly covered by scrubs. Kuznetsov (2000) included records of 5 bat species (Hipposideros armiger, H. bicolor, H. larvatus, Pipistrellus ceylonicus, $P$. javanucus) from $\mathrm{Cu}$ Lao Cham without 
reference to any specimen. Thong (2016) and Thong et al. (2016b) provided the first confirmed records of mammals from $\mathrm{Cu} \mathrm{Lao}$ Cham with reference to observational results and identification of collected specimens. Results from those publications included unusual characteristics of several species (e.g. Cynopterus horsfieldii) and suggested that further research on the bats of $\mathrm{Cu}$ Lao Cham and surroundings is needed.

Located in Quang Ngai province, near $\mathrm{Cu}$ Lao Cham, Ly Son comprises three natural islands, namely $\mathrm{Cu} \mathrm{Lao} \mathrm{Re}, \mathrm{Cu}$ Lao Bo Bai and $\mathrm{Mu} \mathrm{Cu}$. However, $\mathrm{Cu} \mathrm{Lao} \mathrm{Re}$ and $\mathrm{Mu} \mathrm{Cu}$ have been connected by an artificial levee since 2017 (Fig. 1). With high value natural habitats, culture and history, Ly Son has been an attractive destination for tourists since 2007. The development of tourism and agriculture has led to an extraordinary change of natural habitats in the archipelago. Therefore, the remaining natural vegetation within Ly Son has been largely reduced and fragmented. It is remarkable that, prior to 2017, terrestrial plants and animals of the archipelago were unstudied and, as consequence, its vertebrates had never been included in any previous publication. In order to expand knowledge about the bat faunas in $\mathrm{Cu}$ Lao Cham and Ly Son, we conducted a series of field surveys for an assessment of their diversity and conservation status. This paper provides information of the bat species recently recorded over the recent surveys.

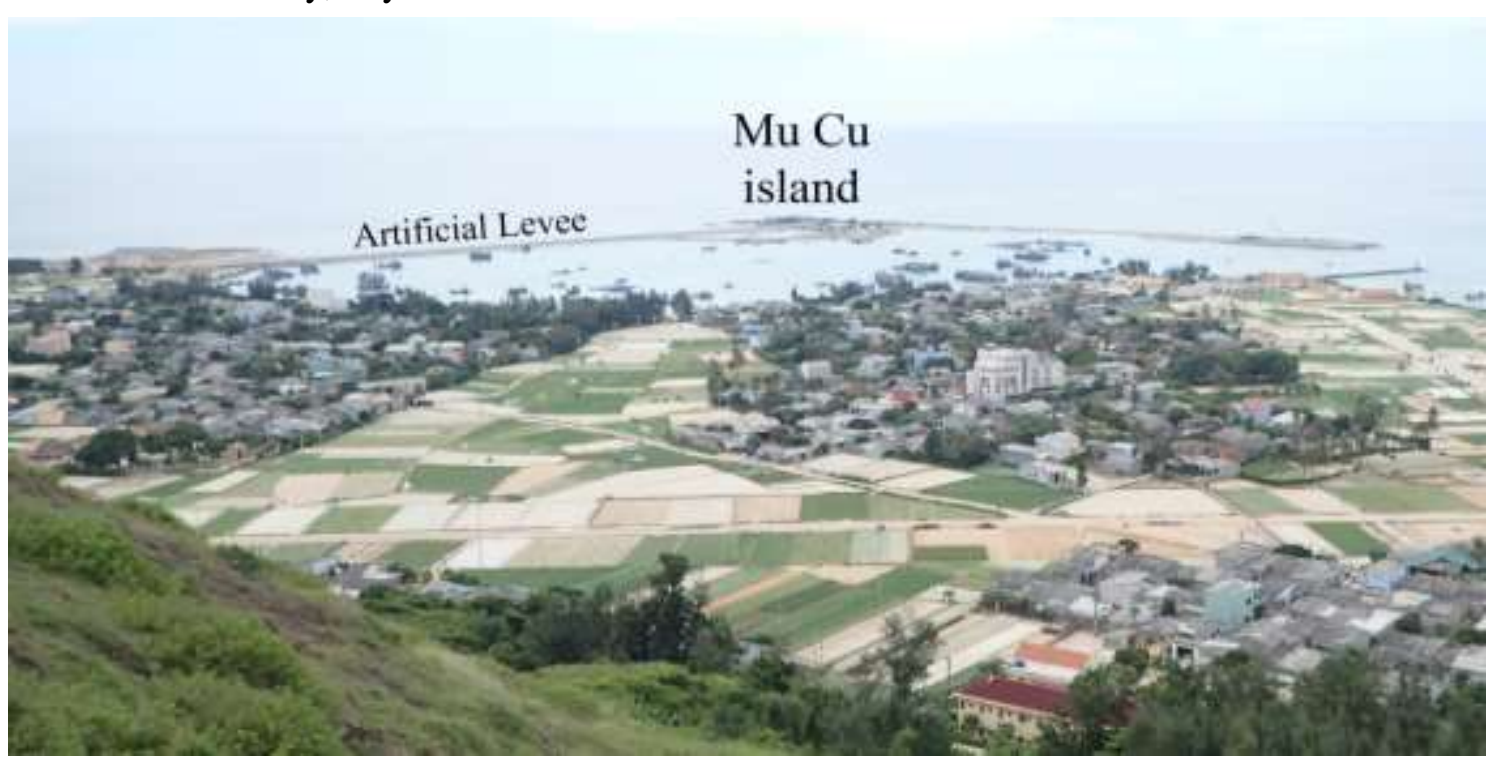

Figure 1. Mu Cu and Cu Lao Re islands of Ly Son have been connected since 2017

\section{MATERIALS AND METHODS}

Methods for conducting field surveys and taking morphological measurements of bats followed those in our previous publications (Thong 2011, 2016): bats were captured and handled in the field following the guidelines approved by the American Society of Mammalogists (Sikes et al., 2016). Four-bank harp traps (Francis 1989) and mist nets of various sizes (2.6 m height, $3-12 \mathrm{~m}$ length) were employed to capture bats. Each captured bat was removed carefully from the traps or nets and placed individually in a cotton bag.

During our surveys between July 2017 and August 2018, we have captured 100 bats. These included three individuals of Megaderma spasma and a series of individuals of Taphozous melanopogon from 
$\mathrm{Cu}$ Lao Cham and one individual of Rhinolophus macrotis from Ly Son. The captured pregnant female of Rhinolophus macrotis was released immediately after a quick identification and taking selected morphological measurements and photos.

The following external measurements were taken using a digital caliper to the nearest $0.1 \mathrm{~mm}$. FA, forearm length-from the extremity of the elbow to the extremity of the carpus with the wings folded; $\mathrm{EH}$, ear heightlength of ear conch; EW, ear width-the greatest width of ear conch; TIB, tibia lengthfrom the knee joint to the ankle; HF, hind-foot length-from the extremity of the heel behind the os calcis to the extremity of the longest digit, excluding hairs or claws; $\mathrm{T}$, tail length-from the anal opening to the tip of the tail. An individual of Megaderma spasma was kept as voucher specimen for confirmed identification with reference to following craniodental features: SL, total length of skull-from occiput to the most anterior part of the canine; CCL, condylocanine length-from the exoccipital condyle to the most anterior part of the canine; IOW, interorbital width-the least width of the interorbital constriction; $\mathrm{ZW}$,

zygomatic width-the greatest width of the skull across the zygomatic arches; C1-C1, upper canine width-greatest width, taken across the outer borders of upper canines; M3-M3, upper molar width-greatest width, taken across the outer crowns of the last upper molars; ml, mandible length-from the anterior rim of the alveolus of the first lower incisor to the most posterior part of the condyle; $\mathrm{c} 1-\mathrm{m}^{3}$, mandibular toothrow length-from the front of the lower canine to the back of the crown of the third lower molar. Methods for preparation of voucher specimen were described in Bates et al. (2005). The above measurements are illustrated in Bates \& Harrison (1997) and Csorba et al. (2003). Reproductive status and age was assessed following Racey (2009) and Brunet-Rossinni and Wilkinson (2009).
Sound recordings were carried out following Thong (2011) and Thong (2016). Echolocation calls of the captured bats were obtained from manual recordings inside a flight-tent $(4 \mathrm{~m}$ [length] $\times 4 \mathrm{~m}$ [width] $\times 2 \mathrm{~m}$ [height]) using a PCTape system at a sampling rate of $480 \mathrm{kHz}$. Batman software, which displays color sonograms of the detected echolocation signals in real time, was used to obtain high quality sound sequences. All recordings were analysed using Selena software to measure the initial frequency (iF) and terminal frequency $(\mathrm{tF})$. The constant frequency of the second harmonic (CF2) of Rhinolophus macrotis was also measured since it is dominant and diagnostic of rhinolophid bats (Thong, 2011). The PCTape system, Batman and Selena software are custom-made by the University of Tübingen, Germany. Morphological and echolocation call parameters of the species from the study sites were compared with the materials from other localities to confirm its taxonomy and supplemental ecological data.

\section{RESULTS AND DISCUSSION}

The black-bearded tomb bat (Taphozous melanopogon) is not only new to $\mathrm{Cu}$ Lao Cham but also known from very few islands in Vietnam. Amongst the archipelagos of Vietnam, several previous publications included Ha Long Bay, Cat Ba, Con Dao and Phu Quoc as parts of distributional range of the species (Huynh et al., 1994; Can et al., 2008; Kruskop 2013). However, the records from Ha Long Bay and Con Dao are unconfirmed because they were unattributable to any specific site or specimen (Thong et al., 2016a; Abramov et al., 2018). On the other hand, an examination of specimens from Phu Quoc is required to confirm its distribution. Therefore, Cat $\mathrm{Ba}$ and $\mathrm{Cu}$ Lao Cham are only two archipelagos of the country with confirmed distribution of this species. It was observed in groups of up to 25 individuals in five small 
adjacent caves within the Sau Eo Gio area, $\mathrm{Cu}$ Lao Cham $\left(15^{\circ} 96.4^{\prime} \mathrm{N} ; 108^{\circ} 51.4^{\prime} \mathrm{E}, 5-15 \mathrm{~m}\right.$ above sea level) on 13 June 2018. With an average FA of $65.0 \mathrm{~mm}$, the captured individuals from $\mathrm{Cu}$ Lao Cham are rather large in comparison with the ones from Cat $\mathrm{Ba}$ (Thong et al., 2016a; Fig. 2). Other morphological characteristics of the individual are similar with those of the individuals from Cat $\mathrm{Ba}$ and other localities in mainland Vietnam (Kruskop 2013; Thong et al., 2016a).
The individuals were captured by Hoang Quoc Huy without equipment for sound recording. A recent study of emballonurid bats including this species indicated that echolocation calls of Taphozous melanopogon from offshore habitats are different in comparison with those of the mainland populations (Thong et al., unpublished data). Therefore, echolocation calls of the $\mathrm{Cu}$ Lao Cham population must be investigated for an acoustic assessment through its distributional range.

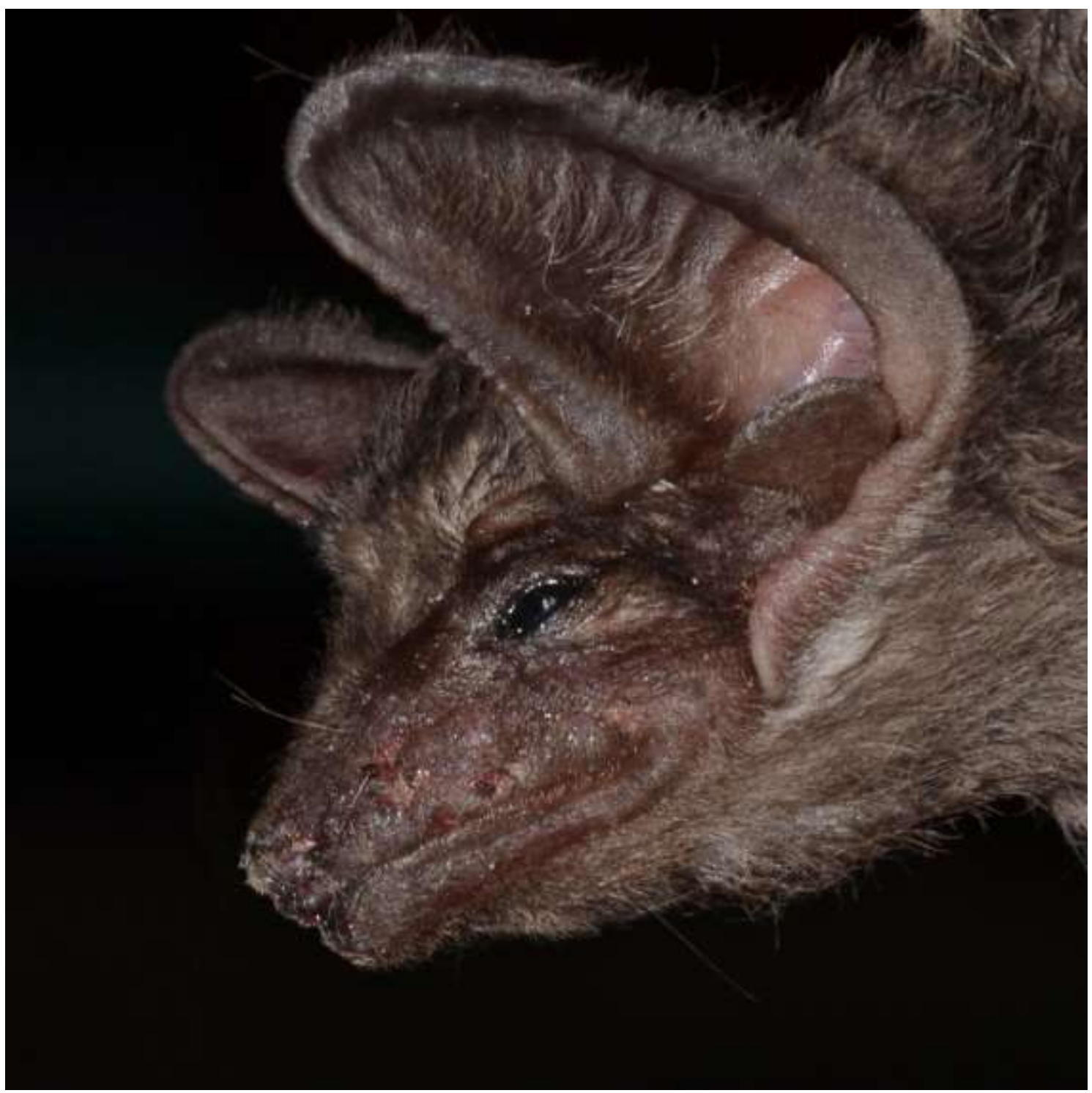

Figure 2. Lateral view of Taphozous melanopogon from $\mathrm{Cu}$ Lao Cham 
The species is listed as "Least Concern" in the current IUCN Red List of Threatened Species (Csorba et al., 2008a). Its known roosting sites in mainland Vietnam and other countries in South Asia have been threatened by "hunting for local consumption and disturbance to roosting sites" and other activities by local people (Csorba et al., 2008a; Vu Dinh Thong, unpublished data). Hunting was not observed in $\mathrm{Cu}$ Lao Cham over the recent surveys but conservation actions are nevertheless necessary to avoid disturbance by local people to its roosting site while rapid development of tourism with some cave visiting tours and road construction takes place around the island.

The lesser false vampire (Megaderma spasma) is a widespread species but mostly recorded in mainland habitats. Within the archipelagos of Vietnam, it was reported from Con Dao and Phu Quoc (Huynh et al., 1994; Kruskop 2013; Abramov et al., 2018). Kruskop (2013) followed Kuznetsov \& Anh (1992) to include Phu Quoc as a part of the species distribution in Vietnam. However, Abramov et al. (2007) did not include Megaderma spasma in a review of mammals from Phu Quoc. Within the Con Dao archipelago, this species was recorded at Con Son island (Abramov et al., 2018). Of the three captured individuals from $\mathrm{Cu}$ Lao Cham, one adult male was captured on 30 May 2017 under a natural vegetation canopy within Bai Bim area $\left(15^{\circ} 57.2^{\prime} \mathrm{N}, 108^{\circ} 31.0^{\prime} \mathrm{E}\right.$, $373 \mathrm{~m}$ above sea level; Fig. 3A); one female was captured on 13 June 2018 among vegetation beside the Bai Huong beach area $\left(15^{\circ} 92.5^{\prime} \mathrm{N}\right.$; $108^{\circ} 53.3^{\prime} \mathrm{E}, 3 \mathrm{~m}$ above sea level) and the remaining female was captured on 30 August 2018 at a small cave within the Bai Huong area $\left(15^{\circ} 92.6^{\prime} \mathrm{N}\right.$; $108^{\circ} 53.1^{\prime} \mathrm{E}, 10 \mathrm{~m}$ above sea level). Both lactating females from the Bai Huong were released after an identification and photography. The male from Bai Bim was kept as a specimen for a comparison with specimens from other localities to confirm the species identification. The specimen (IEBR-T.300517.1) is preserved at the Department of Zoological Museum, Institute of Ecology and Biological Resources, Ha Noi, Vietnam. Its morphological and craniodental measurements are follows: $\mathrm{FA}=60.4 \mathrm{~mm}$, $\mathrm{EH}=42.6 \mathrm{~mm}, \mathrm{EW}=18.9 \mathrm{~mm}, \mathrm{TIB}=33.9$ $\mathrm{mm}, \mathrm{HF}=16.1 \mathrm{~mm}, \mathrm{~T}=46.4 \mathrm{~mm}, \mathrm{SL}=25.7$ $\mathrm{mm}, \quad \mathrm{CCL}=23.1 \mathrm{~mm}, \quad \mathrm{IOW}=$ $3.9 \mathrm{~mm}, \mathrm{ZW}=14.8 \mathrm{~mm}, \mathrm{C} 1-\mathrm{C} 1=5.56 \mathrm{~mm}$, $\mathrm{M} 3-\mathrm{M} 3=10.3 \mathrm{~mm}, \mathrm{ml}=18.2 \mathrm{~mm}$ and $\mathrm{c} 1-\mathrm{m}^{3}$ $=11.3 \mathrm{~mm}$. These measurements and other morphological characteristics of the captured individuals are similar with descriptions in previous publications (Bates and Harrison 1997; Kruskop 2013). Prior to the present study, echolocation of Megaderma spasma from Vietnam was poorly documented. In India, the species uses a multiharmonic broadband frequency-modulated (FM) calls (Raghuram et al., 2014; Vanitherani et al., 2015). The male from $\mathrm{Cu}$ Lao Cham also uses multiharmonic FM calls with values of $\mathrm{iF}$ and tF of $92.1 \mathrm{kHz}$ and $14.6 \mathrm{kHz}$, respectively (Fig. 3B). In comparison with those from India, the $\mathrm{iF}$ value of the bats from $\mathrm{Cu} \mathrm{Lao}$ Cham is much higher while the $\mathrm{tF}$ is nested within the known variation of 8.1-24.2 kHz (Raghuram et al., 2014; Vanitherani et al., 2015). It is likely that the echolocation frequencies of the species from India and Vietnam are in a narrow variation. However, comparison of sound measurements of FM bat species would be more reliable when field surveys and experiments were implemented following the same protocol and equipment. This species is also listed as "Least Concern" in the current IUCN Red List of Threatened Species (Csorba et al. 2008b). A colony of fewer than 10 individuals was observed at an unnamed small cave within the Bai Huong area of $\mathrm{Cu}$ Lao Cham. There is no major threat to the current population of the species in $\mathrm{Cu}$ Lao Cham but conservation of its roosting cave is also needed to avoid disturbance by future tourist developments. 
The big-eared horseshoe bat (Rhinolophus macrotis) is a member of the "Rhinolophus philippinensis group" (Csorba et al. 2003). It is a widespread species but rarely recorded from island habitats. Within the archipelagos of Vietnam, the species was only recorded from Cat Ba (Thong 2014). Over the field surveys of this study, only one pregnant female was captured in $\mathrm{Cu}$ Lao Re island (Fig. 4A). To date, Rhinolophus macrotis is still regarded as a complicated species complex. To our knowledge, the complex comprises at least two distinct species (Thong, 2003; Molur et al. 2008; Sun et al., 2008; Thong, 2011; Loi \& Thong, 2017; Sun et al., 2016; Thanh, 2018). Sun et al. (2008) provisionally identified as Rhinolophus macrotis "large" and Rhinolophus macrotis "small". The individual captured at Ly Son belongs to the later species. It is a medium-sized horseshoe bat with a FA and EH of $39.1 \mathrm{~mm}$ and $20.6 \mathrm{~mm}$ respectively. Other external measurements are as follows: $\mathrm{EW}=12.5 \mathrm{~mm}$, $\mathrm{TIB}=16.6 \mathrm{~mm}, \mathrm{HF}=6.8 \mathrm{~mm}, \mathrm{~T}=20.4 \mathrm{~mm}$. The pelage is dark-brown and the hair tips are darker than the rest of respective hairs. Other morphological features are similar to descriptions in previous publications (Csorba et al., 2003; Thong 2011; Kruskop 2013). The taxonomic status of Rhinolophus macrotis sensu lato and the whole "philippinensis group" is still under discussion although several researchers had investigated different genes (Zhang et al., 2018).
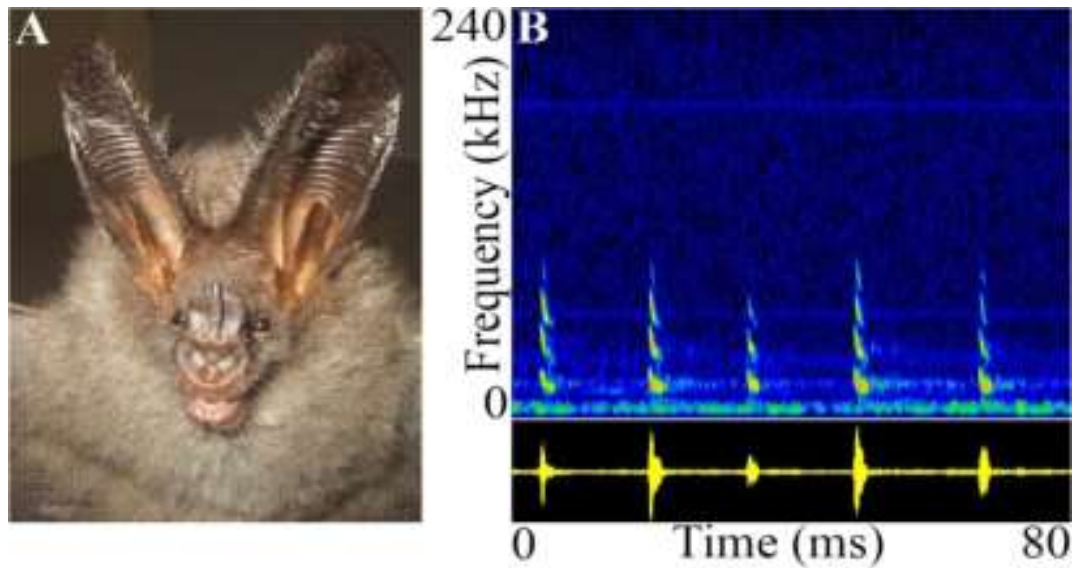

Figure 3. Fontal view (A) and a sonogram of echolocation call (B) of Megaderma spasma from $\mathrm{Cu}$ Lao Cham
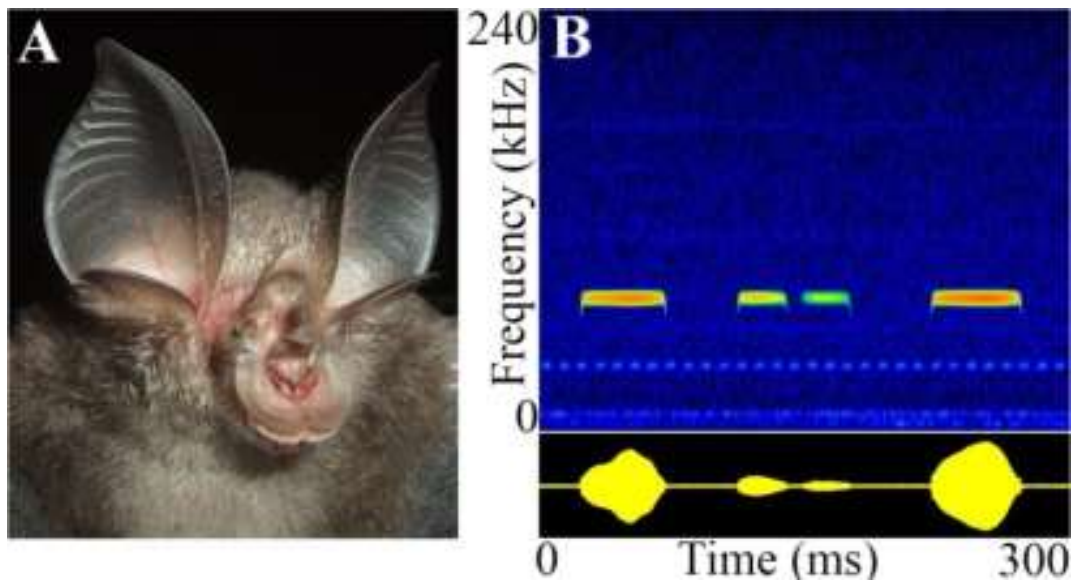

Figure 4. Frontal view (A) and a sonogram of echolocation call (B) of Rhinolophus macrotis from Ly Son 
Rhinolophus macrotis "small" uses the multiharmonic call of the genus Rhinolophus. Each harmonic consists of three distinct portions: an initial modulated frequency, constant frequency (CF) phase and the terminal modulated frequency (Fig. 4B). When flying inside the flight tent, the captured individual emitted CF2 of $75.1 \mathrm{kHz}$ which is almost identical to that of the calls when the bat was released. This CF2 value is rather higher than that of the population on Cat Ba island (Thong, 2014).

Rhinolophus macrotis sensu lato is regarded as as "Least Concern" in the current IUCN Red List of Threatened Species (Molur et al., 2008). As mentioned above, the species is rarely recorded from islands of Vietnam. Prior to the present study, Cat Ba was the only island in the country with records of this species (Thong, 2014). Molur et al. (2008) noted that the species "is associated with limestone caves at an altitude of around 1,000 $m$ asl". However, the individual from Ly Son was captured at a footpath near a fruit tree garden which is not associated with any karst habitat. There is no major threat to the species population in Ly Son. Habitats of the population in the island would be disturbed or threatened by some conversion of the remaining natural vegetation area for agricultural use.

\section{CONCLUSION}

Morphology and echolocation features of Megaderma spasma, Taphozous melanopogon and Rhinolophus macrotis are similar to respective populations from mainland and other islands of Vietnam.

Megaderma spasma, Taphozous melanopogon and Rhinolophus macrotis are uncommon within the $\mathrm{Cu}$ Lao Cham and $\mathrm{Ly}$ Son archipelagos. There are no major threats to these species populations within these two archipelagos. However, without timely and practical conservation campaigns, their roosts and foraging habitats would be threatened by some expansion of areas for tourism in $\mathrm{Cu}$ Lao Cham and agriculture in Ly Son.

Acknowledgements: This research is funded by the Vietnam Academy of Science and Technology (VAST) under project number VAST04.10/17-18 and the Vietnam National Foundation for Science and Technology Development (NAFOSTED) under the grant number 106.05-2017.35. The authors are very grateful to Prof. Hans-Ulrich Schnitzler, Dr. Annette Denzinger, Dr. Christian Dietz of the University of Tuebingen, Germany for support for acoustic research; and to our colleagues in the Tay Bac University and the Institute of Ecology and Biological Resources and other institutions for their help and support.

\section{REFERENCES}

Abramov A. V., Kalinin A. A., Morozov P. N., 2007. Mammal survey on Phu Quoc Island, southern Vietnam. Mammalia, 71(1-2): 40-46.

Abramov A. V., Kruskop S. V., Shchinov A. V., 2018. Mammals of Con Son Island, southern Vietnam. Russian Journal of Theriology, 17(1): 1-16.

Bates P. J. J., Harrison D. L., 1997. Bats of the Indian Subcontinent. Harrison Zoological Museum. Sevenoaks. Kent. United Kingdom, 250 pp.

Bates P. J. J., Thong V. D., Bumrungsri S., 2005. Voucher specimen preparation: bats. Harrison Institute, Kent, England: $13 \mathrm{pp}$.

Brunet-Rossinni A. K., Wilkinson G. S., 2009. Methods for age estimation and the study of senescence in bats. In: (T. H. Kunz and S. Parsons. eds.). Ecological and behavioral methods for the study of bats. 2nd ed. Johns Hopkins University Press. Baltimore. Maryland, pp. 315-325. 
Can D. N., Endo H., Son N. T., Oshida T., Canh L. X., Phuong D. H., Lunde D. P., Kawada S.-I., Hayashida A., Sasaki M., 2008. Checklist of wild mammal species of Vietnam. Ha Noi: Primate Research Institute, Inuyama, Japan and Institute of Ecology and Biological Resources: pp. 68-182 [in Vietnamese].

Csorba G., Bumrungsri S., Helgen K., Francis C., Bates P., Gumal M., Balete D., Heaney L., Molur S., Srinivasulu C., 2008a. Taphozous melanopogon. The IUCN Red List of Threatened Species 2008.

http://dx.doi.org/10.2305/IUCN.UK.2008. RLTS.T21461A9281177.en. Downloaded on 01 January 2019.

Csorba G., Bumrungsri S., Helgen K., Francis C., Bates P., Gumal M., Kingston T., Heaney L., Balete D., Esselstyn J., Molur S., Srinivasulu C., 2008b. Megaderma spasma. The IUCN Red List of Threatened

Species 2008. http://dx.doi.org/10.2305/I UCN.UK.2008.RLTS.T12939A3399869.e n. Downloaded on 01 January 2019.

Csorba G., Ujhelyi P., Thomas N., 2003. Horseshoe Bats of the World (Chiroptera: Rhinolophidae). Alana Books. Shropshire. United Kingdom, 160 pp.

Francis C. M., 1989. A comparison of mist nets and two types of harp traps for capturing bats. Journal of Mammalogy, 70(4): 865-870.

Huynh D. H. (edit.), Sung C. V., Tien D. V., Anh P. T., Khien H. M., 1994. Checklist of mammals in Vietnam. Publishing House Science and Technics, Hanoi: $168 \mathrm{pp}$.

Kruskop S. V., 2013. Bats of Vietnam Checklist and an identification manual. Joint Russian-Vietnamese Science and Technological Tropical Centre. Moscow. Russia: 316 pp.
Kuznetsov G. V., Anh P. T., 1992. Mammals of coastal islands of Vietnam (biogeographical and ecological aspects). In: Zoological studies in Vietnam, Nauka, Moscow, pp. 182-197 [in Russian].

Loi D. N., Thong V. D., 2017. First records of bats (Mammalia: Chiroptera) from Muong Phang Cultural and Historical Site, Dien Bien province, Northeastern Vietnam. Journal of Biology, 39(3): 396-402.

Molur S., Srinivasulu C., Francis C., 2008. Rhinolophus macrotis. The IUCN Red List of Threatened Species 2008. https://doi.org/10.2305/IUCN.UK.2 008.RLTS.T19550A8974366.en. (Accessed 01 January, 2019).

Racey P. A., 2009. Reproductive assessment of bats. In: (T. H. Kunz and S. Parsons. eds.). Ecological and behavioral methods for the study of bats. 2nd ed. Johns Hopkins University Press. Baltimore. Maryland, pp. 249-264.

Raghuram H., Jain M., Balakrishnan R., 2014. Species and acoustic diversity of bats in a palaeotropical wet evergreen forest in southern India. Current Science, 107(4): 631-641.

Sikes R. S., the Animal Care and Use Committee of the American Society of Mammalogists, 2016. 2016 Guidelines of the American Society of Mammalogists for the use of wild mammals in research and education. Journal of Mammalogy, 97(3): 663-688.

Sun K.-P., Feng J., Jiang T. L., Ma J., Zhang Z.-Z., Jin L.-R., 2008. A new cryptic species of Rhinolophus macrotis (Chiroptera: Rhinolophidae) from Jiangxi Province, China. Acta Chiropterologica, 10(1): 1-10.

Sun K., Kimball R. T., Liu T., Wei X., Jin L., Jiang T., Lin A., Feng J., 2016. The complex evolutionary history of big-eared horseshoe bats (Rhinolophus macrotis 
New records of bats (Mammalia: Chiroptera)

complex): insights from genetic, morphological and acoustic data. Scientific reports, 6: 35417.

Thanh H. T., 2018. Study on horseshoe bats (Chiroptera: Rhinolophidae) of Vietnam. $\mathrm{PhD}$ Thesis, VNU University of Science, Ha Noi: 154pp.

Thong V. D., 2003. A preliminary survey of the bat fauna of Pu Luong Nature Reserve, Thanh Hoa province, north-central Vietnam. Unpublished report to the $\mathrm{Pu}$ Luong-Cuc Phuong Conservation Limestone Landscape Conservation Project: 36pp.

Thong V. D., 2011. Systematics and echolocation of rhinolophoid bats (Mammalia: Chiroptera) in Vietnam. PhD Thesis, University of Tuebingen, Tuebingen, Germany.

Thong V. D., 2014. Acoustic identification and taxonomic remarks of horseshoe bats (Chiroptera: rhinolophidae) in $\mathrm{Cat} \mathrm{Ba}$ National Park, north-eastern Vietnam. Proceedings of the first international VAST-BAS conference: 323-328.

Thong V. D., 2016. An assessment of diversity and current status of bats in $\mathrm{Cu}$ Lao Cham-Hoi An biosphere reserve. Journal of Biology, 38(1): 33-38.

Thong V. D., Dung D. T., Thanh N. V., 2016a. An overview of bat research in Cat $\mathrm{Ba}$ biosphere reserve with remarks on previous records. Proceedings of the $2^{\text {nd }}$ national scientific conference on biological research and teaching in Vietnam. Publishing House of the Vietnam National University: 737-744 [in Vietnamese].

Thong V. D., Nghia N. X., Luong N. T., 2016b. Diversity of mammals from $\mathrm{Cu}$ Lao Cham Marine Protected Area. Proceedings of the $2^{\text {nd }}$ national scientific conference on biological research and teaching in Vietnam. Publishing House of the Vietnam National University: 732-736 [in Vietnamese].

Thong V.D., Thanh, H. T., Huyen N. T. T., Loi D. N., Viet N. V., Anh D. T., Sang N. V., [submitted to Mammalia journal, in review]. First records of bats (Mammalia: Chiroptera) from Ly Son Archipelago, Central Vietnam, with remarks on echolocation of Myotis muricola.

Vanitharani J., Mercy, Ponmalar S., Petchiammal., 2015. Indian False Vampire Bats (Carnivore), the Health Managers of Forest and Agroecosystems. Scrutiny International Research Journal of Biological and Environmental Science, 2(8): 7-20.

Zhang L., Sun K., Liu T., Zhao H., Csorba G., Jin L., Thong V. D., Feng J., 2018. Multilocus phylogeny and species delimitation within the philippinensis group (Chiroptera: Rhinolophidae). Zoologica Scripta: 1-18. 
